\title{
RESEARCH
}

Open Access

\section{The phosphodiesterase 10 inhibitor papaverine exerts anti-inflammatory and neuroprotective effects via the PKA signaling pathway in neuroinflammation and Parkinson's disease mouse models}

Yu-Young Lee ${ }^{1+}$, Jin-Sun Park ${ }^{1+}$, Yea-Hyun Leem ${ }^{1}$, Jung-Eun Park' ${ }^{1}$ Do-Yeon Kim', Youn-Hee Choi², Eun-Mi Park ${ }^{3,4}$, Jihee Lee Kang ${ }^{2}$ and Hee-Sun Kim ${ }^{1,4^{*}}$ (D)

\begin{abstract}
Background: Neuroinflammation plays a pivotal role in the pathogenesis of Parkinson's disease (PD). Thus, the development of agents that can control neuroinflammation has been suggested as a promising therapeutic strategy for PD. In the present study, we investigated whether the phosphodiesterase (PDE) 10 inhibitor has antiinflammatory and neuroprotective effects in neuroinflammation and PD mouse models.

Methods: Papaverine (PAP) was utilized as a selective inhibitor of PDE10. The effects of PAP on the expression of pro-inflammatory molecules were examined in lipopolysaccharide (LPS)-stimulated BV2 microglial cells by ELISA, RT-PCR, and Western blot analysis. The effects of PAP on transcription factors were analyzed by the electrophoretic mobility shift assay, the reporter gene assay, and Western blot analysis. Microglial activation and the expression of proinflammatory molecules were measured in the LPS- or MPTP-injected mouse brains by immunohistochemistry and RT-PCR analysis. The effect of PAP on dopaminergic neuronal cell death and neurotrophic factors were determined by immunohistochemistry and Western blot analysis. To assess mouse locomotor activity, rotarod and pole tests were performed in MPTP-injected mice.

Results: PAP inhibited the production of nitric oxide and proinflammatory cytokines in LPS-stimulated microglia by modulating various inflammatory signals. In addition, PAP elevated intracellular CAMP levels and CREB phosphorylation. Treatment with H89, a PKA inhibitor, reversed the anti-inflammatory effects of PAP, suggesting the critical role of PKA signaling in the anti-inflammatory effects of PAP. We verified the anti-inflammatory effects of PAP in the brains of mice with LPS-induced systemic inflammation. PAP suppressed microglial activation and proinflammatory gene expression in the brains of these mice, and these effects were reversed by H89 treatment. We further examined the effects of PAP on MPTP-injected PD model mice. MPTP-induced dopaminergic neuronal cell death and impaired locomotor activity were recovered by PAP. In addition, PAP suppressed microglial activation and proinflammatory mediators in the brains of MPTP-injected mice.

(Continued on next page)
\end{abstract}

\footnotetext{
* Correspondence: hskimp@ewha.ac.kr

${ }^{\dagger}$ Yu-Young Lee and Jin-Sun Park contributed equally to this work.

1 Department of Molecular Medicine and Tissue Injury Defense Research

Center, School of Medicine, Ewha Womans University, 808-1 Magok-dong,

Gangseo-gu, Seoul 07804, South Korea

${ }^{4}$ Department of Brain \& Cognitive Sciences, Ewha Womans University, Seoul,

South Korea

Full list of author information is available at the end of the article
}

(c) The Author(s). 2019 Open Access This article is distributed under the terms of the Creative Commons Attribution 4.0 International License (http://creativecommons.org/licenses/by/4.0/), which permits unrestricted use, distribution, and

reproduction in any medium, provided you give appropriate credit to the original author(s) and the source, provide a link to the Creative Commons license, and indicate if changes were made. The Creative Commons Public Domain Dedication waiver (http://creativecommons.org/publicdomain/zero/1.0/) applies to the data made available in this article, unless otherwise stated. 
(Continued from previous page)

Conclusions: PAP has strong anti-inflammatory and neuroprotective effects and thus may be a potential candidate for treating neuroinflammatory disorders such as PD.

Keywords: Parkinson's disease, Neuroinflammation, Neuroprotection, Microglia, PDE10 inhibitor, Papaverine, PKA signaling

\section{Background}

Neuroinflammation plays an important role in the development and progression of neurodegenerative diseases such as Parkinson's disease (PD), Alzheimer's disease, and Huntington's disease (HD) $[1,2]$. Microglia are the resident immune cells of the brain, and play a pivotal role in neuroinflammation. Microglia are readily activated following brain injury, during neurodegenerative processes, or upon interaction with misfolded proteins or invading pathogens. These cells then quickly proliferate, become hypertrophic, and secrete proinflammatory cytokines and neurotoxic factors [3, 4]. A prolonged and unresolved inflammatory response leads to destructive chronic inflammation (neuroinflammation), which results in neuronal cell death and the onset of neurodegenerative diseases $[5,6]$. PD is characterized by impairment of the nigrostriatal dopaminergic system, which involves a severe loss of nigral neurons and a decrease in striatal dopaminergic input. In addition, the intracellular inclusion of $\alpha$-synuclein is closely related to sustained neuroinflammation $[7,8]$. The levels of pro-inflammatory cytokines are increased in the brain and cerebrospinal fluid of PD patients [9]. Thus, controlling microglial activation has been suggested as an important therapeutic strategy for neurodegenerative diseases.

Cyclic AMP (cAMP; 3',5'-adenosine cyclic monophosphate), a second messenger in intracellular signaling, is known to regulate microglial function and activation $[10,11]$. Moreover, recent studies have reported that cAMP is a critical determinant in the M1-M2 polarization of microglia $[12,13]$. Intracellular cAMP level is controlled by phosphodiesterases (PDEs), enzymes that catalyze the hydrolysis of phosphodiester bonds and convert cyclic nucleotides into non-cyclic forms. There exist several reports demonstrating that PDE inhibitors exert anti-inflammatory effects in neuroinflammatory conditions. The PDE4 inhibitor FFPM improved learning and memory in APP/PS1 transgenic mice via its anti-inflammatory effect mediated through PKA/CREB signaling [14]. In addition, ibudilast, a non-selective PDE inhibitor, attenuated neuroinflammation by inhibiting astroglial reactivity in a MPTP mouse model of PD [15]. Until now, studies into the suppression of neuroinflammation by PDE inhibitors have mainly focused on PDE4, a predominant negative regulator of cAMP signaling within microglia [7]. Although the most common PDE4 inhibitor, rolipram, reached clinical trials, it later failed due to significant side effects $[16,17]$. More recently developed inhibitors are also limited in their therapeutic role due to a lack of brain penetration [13]. Therefore, the development of a blood-brain barrier (BBB)-permeable PDE inhibitor with minimal side effects is necessary.

Papaverine (PAP; 6,7-dimethoxy-1-veratryl-isoquinoline) is a non-narcotic opium alkaloid isolated from Papaver somniferum, the opium poppy [18]. PAP is used clinically as a vasodilator and smooth muscle relaxant in conditions associated with spasm and dysmotility of the gastrointestinal and urinary tracts $[19,20]$. PAP is a selective inhibitor of PDE10A, which is markedly expressed in the striatum of the brain $[21,22]$, specifically in the caudate nucleus, nucleus accumbens, and olfactory tubercle [23]. In addition, PDE10A has also been detected in parenchymal parts of the substantia nigra, globus pallidus, and striatonigral projections [24]. Therefore, several studies have suggested PDE10A as a potential therapeutic target for movement disorders such as PD and HD, and psychiatric disorders that affect the basal ganglia [25-27]. Currently, several PDE10A inhibitors are undergoing clinical trials in patients with HD and schizophrenia [28, 29]. Several studies have already identified therapeutic effects of PAP. PAP improved cognitive impairment in a HD mouse model by increasing GluA1 and CREB phosphorylation [30]. Moreover, PAP showed anti-inflammatory effects in mouse models of optic neuropathy, LPS-stimulated macrophages/microglia, and high mobility group box 1mediated inflammatory responses [31-34].

Although previous studies have reported the various pharmacological activities of PAP, its effects on neuroinflammation and neurodegeneration have not been clearly demonstrated. Therefore, in the present study, we investigated whether PAP has therapeutic effects in neuroinflammation and PD mouse models. We found that PAP has anti-inflammatory effects in LPS-induced neuroinflammatory conditions, both in vitro and in vivo. We also demonstrated the neuroprotective and anti-inflammatory effects of PAP in MPTP-induced PD model mice. Further mechanistic studies revealed that the anti-inflammatory and neuroprotective effects of PAP are mediated through the PKA signaling pathway.

\section{Methods \\ Animals}

Adult male ICR (28-32 g, 8 weeks old) and C57BL/6 (22-25 g, 8 weeks old) mice were purchased from Orient 
Bio Inc. (Seongnam, Korea), a branch of Charles River Laboratories. Mice were housed at $21^{\circ} \mathrm{C}$ under a $12 \mathrm{~h}$ light: $12 \mathrm{~h}$ dark cycle, and had ad libitum access to water and rodent chow. Every effort was made to minimize stress to the animals. All experiments were performed in accordance with the National Institutes for Health and Ewha Womans University guidelines for Laboratory Animals Care and Use, and the study was approved by the Institutional Animal Care and Use Committee of the Medical School of Ewha Womans University (\#ESM 15-0321).

\section{Reagents and antibodies}

LPS (Escherichia coli serotype 055:B5), papaverine, H89, and antibodies against BDNF, iNOS, and $\beta$-actin were obtained from Sigma-Aldrich (St Louis, MO, USA). MPTP was purchased from Tokyo Chemical Industry Co. (Tokyo, Japan). Antibodies against phosphorylated and total Akt, MAPKs, and CREB were purchased from Cell Signaling Technology (Beverley, CA, USA). An antibody against phospho-p47phox was purchased from Assaybiotech (Sunnyvale, CA, USA). Antibodies against TNF- $\alpha$, IL-1 $\beta$, CD11b, lamin A, PDE10, and TH were purchased from Santa Cruz Biotechnology (Santa Cruz, CA, USA). Antibodies against IL-10, Bcl2, PGC-1 $\alpha$, and GDNF were purchased from Abcam (Cambridge, UK). An antibody against Iba-1 was purchased from Wako (Osaka, Japan). All RT-PCR enzymes and chemicals and electrophoretic mobility shift assay (EMSA) oligonucleotides were purchased from Promega (Madison, WI, USA). All other chemicals were obtained from SigmaAldrich, unless otherwise stated.

\section{Microglial cell culture and cell viability test}

The immortalized mouse BV2 microglial cell line [35] was grown and maintained in Dulbecco's modified Eagle medium supplemented with $10 \%$ heat-inactivated fetal bovine serum, streptomycin $(10 \mu \mathrm{g} / \mathrm{mL})$, and penicillin $(10 \mathrm{U} / \mathrm{mL})$ at $37^{\circ} \mathrm{C}$ under $5 \% \mathrm{CO}_{2}$. Primary microglial cells were cultured from the cerebral cortices of 1- to 2day-old Sprague-Dawley rat pups as described previously [36]. The purity of the microglial cultures was $>95 \%$, as confirmed by Western blot and immunocytochemistry analyses using an antibody specific to ionized calcium binding adapter protein-1 (Iba-1; data not shown). Cell viability was determined using the 3-(4,5-dimethylthiazol-2-yl)-2,5-diphenyl tetrazolium bromide (MTT) reduction assay, as previously described [37].

\section{Measurement of cytokine, nitrite, intracellular ROS, and cAMP levels in BV2 cells}

BV2 cells $\left(1 \times 10^{5}\right.$ cells per well in a 24 -well plate $)$ were pretreated with PAP $1 \mathrm{~h}$ prior to LPS stimulation (100 $\mathrm{ng} / \mathrm{mL}$ ) for $16 \mathrm{~h}$. The supernatants of the cultured cells were collected and the concentrations of TNF- $\alpha$, IL- $1 \beta$, and IL-10 were measured by an enzyme-linked immunosorbent assay (ELISA) with a kit supplied from BD Biosciences (San Jose, CA, USA). Accumulated nitrite levels were measured using Griess reagent (Promega, Madison, WI). The intracellular accumulation of ROS was measured with $\mathrm{H}_{2}$ DCF-DA (Sigma-Aldrich, St. Louis, MO), as previously described [38]. To determine the effect of PAP on intracellular cAMP level, BV2 cells were treated with PAP with or without LPS stimulation for $30 \mathrm{~min}$, and cAMP level was measured using a cAMP ELISA kit from Enzo Life Sciences (Farmingdale, NY, USA).

\section{Reverse-transcription polymerase chain reaction}

Total RNA from BV2 cells and mouse brain tissue was extracted using TRIzol reagent (Invitrogen, CA, USA). For RT-PCR, $1 \mu \mathrm{g}$ RNA was reverse transcribed in a reaction mixture containing $1 \mathrm{U}$ RNase inhibitor, $500 \mathrm{ng}$ random primer, $3 \mathrm{mM} \mathrm{MgCl}_{2}, 0.5 \mathrm{mM}$ dNTP, 1X RT buffer, and $10 \mathrm{U}$ reverse transcriptase (Promega, Madison, WI). The synthesized cDNA was used as a template for the PCR reaction using Go Taq polymerase (Promega) and primers for target genes. RT-PCR was carried out in a Bio-Rad T100 thermal cycler (Bio-Rad, Richmond, CA). Quantitative RT-PCR was performed on an ABI PRISM 7000 Sequence Detection System (Applied Biosystems, Foster City, CA) with Sensi FAST ${ }^{\mathrm{rm}}$ SYBR Hi-ROX Mix (Bioline, London, UK). The expression levels of the target genes were normalized against that of

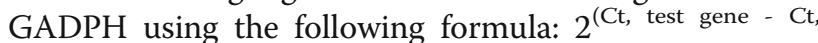
GAPDH). The primer sequences used in the PCR reactions are shown in Table 1.

\section{Electrophoretic mobility shift assay}

BV2 cells were pretreated with PAP for $1 \mathrm{~h}$ and stimulated with LPS for $3 \mathrm{~h}$. The nuclear extracts from the cells were prepared as previously described [36]. Doublestranded DNA oligonucleotides containing the NF- $\mathrm{B}$, $\mathrm{AP}-1, \mathrm{ARE}$, and CRE consensus sequences were end labeled using T4 polynucleotide kinase (New England Biolabs, Beverly, MA) in the presence of $\left[\gamma^{-32} \mathrm{P}\right] \mathrm{ATP}$. Nuclear proteins $(5 \mu \mathrm{g})$ were then incubated with a ${ }^{32} \mathrm{P}$ labeled probe on ice for $30 \mathrm{~min}$, resolved on a $5 \%$ acrylamide gel, and visualized by autoradiography.

\section{Western blot analysis}

Whole cell protein lysates and brain tissue homogenates were prepared in a lysis buffer (10 mM Tris ( $\mathrm{pH} 7.4), 30$ $\mathrm{mM} \mathrm{NaCl}, 1 \%$ Triton $\mathrm{X}-100,0.1 \%$ SDS, $0.1 \%$ sodium deoxycholate, and $1 \mathrm{mM}$ EDTA) containing a protease inhibitor cocktail. Protein samples were separated by SDS-PAGE, transferred to a nitrocellulose membrane, and incubated with primary antibodies according to the manufactures' directions for dilution (Additional file 1: Table S1). After thoroughly washing with TBST, HRP- 
Table 1 Primer sequences used for PCR

\begin{tabular}{|c|c|c|c|}
\hline Gene & Forward primer $\left(5^{\prime} \rightarrow 3^{\prime}\right)$ & Reverse primer $\left(5^{\prime} \rightarrow 3^{\prime}\right)$ & Size \\
\hline TNF-a & CCTATGTCTCAGCCTCTTCT & CCTGGTATGAGATAGCAAAT & $354 \mathrm{bp}$ \\
\hline iNOS & CAAGAGTTTGACCAGAGGACC & TGGAACCACTCGTACTTGGGA & $450 \mathrm{bp}$ \\
\hline $\mid L-1 \beta$ & GGCAACTGTTCCTGAACTCAACTG & CCATTGAGGTGGAGAGCTTTCAGC & $447 \mathrm{bp}$ \\
\hline IL-6 & CACGATTTCCCAGAGAACATGTG & ACAACCACGGCCTTCCCTACTT & $128 \mathrm{bp}$ \\
\hline IL-10 & GCCAGTACAGCCGGGAAGACAATA & GCCTTGTAGACACCTTGGTCTT & $409 \mathrm{bp}$ \\
\hline MMP-3 & ATTCAGTCCCTCTATGGA & CTCCAGTATTTGTCCTCTAC & $375 \mathrm{bp}$ \\
\hline MMP-8 & CCAAGGAGTGTCCAAGCCAT & CCTGCAGGAAAACTGCATCG & $180 \mathrm{bp}$ \\
\hline p47phox & CGATGGATTGTCCTTTGTGC & ATCACCGGCTATTTCCCATC & $256 \mathrm{bp}$ \\
\hline p67phox & CCCTTGGTGGAAGTCCAAAT & ATCCTGGATTCCCATCTCCA & $242 \mathrm{bp}$ \\
\hline gp91phox & ACTGCGGAGAGTTGGAAGA & GGTGATGACCACCTITTGCT & $201 \mathrm{bp}$ \\
\hline p22phox & AAAGAGGAAAAAGGGGTCCA & TAGGCTCAATGGGAGTCCAC & $239 \mathrm{bp}$ \\
\hline TLR2 & GAGCGAGCTGGGTAAAGTAG & AGCCGAGGCAAGAACAAAGA & $528 \mathrm{bp}$ \\
\hline TLR4 & GAGATGAATACCTCCTTAGTGTTGG & ATTCAAAGATACACCAACGGCTCTGA & $414 \mathrm{bp}$ \\
\hline GAPDH & TTCACCACCATGGAGAAGGC & GGCATGGACTGTGGTCATGA & $245 \mathrm{bp}$ \\
\hline
\end{tabular}

conjugated secondary antibodies (BioRad, Hercules, CA, USA 1:1000 dilution in TBST) were applied, and the blots were developed using an enhanced chemiluminescence detection kit (Thermo Fisher Scientific, Waltham, MA, USA). For quantification, the density of specific target bands was normalized against $\beta$-actin, using ImageJ software, version 1.37 (National Institutes of Health, Bethesda, MD).

\section{Transient transfection and luciferase assay}

BV2 cells $\left(2 \times 10^{5}\right.$ cells/well on a 12 -well plate $)$ were transfected with $1 \mu \mathrm{g}$ of reported plasmid DNA using Metafectene transfection reagent (Biontex, Martinsried/ Planegg, Germany). The effect of PAP on reporter gene activity was determined by pre-treating the cells with PAP prior to stimulation with LPS $(100 \mathrm{ng} / \mathrm{mL})$ for $6 \mathrm{~h}$. After preparing the cell lysates, the luciferase assay was performed as previously described [36].

\section{Drug administration}

ICR mice were randomly divided into six groups (control, LPS, LPS+PAP, LPS+PAP+H89, PAP, and H89; each group, $n=8-10)$. H89 (1 mg/kg, i.p.) was administrated $1 \mathrm{~h}$ before PAP (30 mg/kg/day, i.p.) for four consecutive days. A single injection of LPS $(5 \mathrm{mg} / \mathrm{kg}$, i.p.) was administered $1 \mathrm{~h}$ after the final PAP administration as previously described [36]. For studying the MPTP mouse model, C57/BL6 mice were divided into six groups (control, MPTP, MPTP+PAP, MPTP+PAP+H89, $\mathrm{PAP}$, and H89; each group, $n=12-14)$. H89 $(1 \mathrm{mg} / \mathrm{kg}$, i.p.) was administrated $1 \mathrm{~h}$ before PAP $(30 \mathrm{mg} / \mathrm{kg} /$ day, i.p.) for three consecutive days. One day after the final PAP treatment, MPTP (20 mg/kg, i.p) was injected four times with 2-h intervals [39].

\section{Behavioral test}

To assess mouse motor coordination, the rotarod test (20-21 rpm, 600 s), modified from a previous method [40], was performed 1, 3, and 7 days after MPTP injection. Before the principal test, all mice were trained on the rotarod (18-19 rpm) until no fall was observed in $300 \mathrm{~s}$. To evaluate dyskinesia, the pole test $(50 \mathrm{~cm}$ in height, $0.7 \mathrm{~cm}$ in diameter, $120 \mathrm{~s}$ ) was implemented 6 days after MPTP injection. Similarly, prior to the principal test, mice were trained three times to successfully descend from the top to the bottom of the pole.

\section{Brain tissue preparation}

For histological analysis, the mice were anesthetized with sodium pentobarbital $(80 \mathrm{mg} / \mathrm{kg}$ body weight, i.p. injection) and were then transcardially perfused with $0.9 \%$ saline followed by $4 \%$ paraformaldehyde for tissue fixation. The brains were then isolated and stored in 30\% sucrose solution at $4{ }^{\circ} \mathrm{C}$ for cryoprotection. For biochemical analysis, the mice were transcardially perfused with saline. The striatum and substantia nigra were dissected from each brain according to the Paxinos mouse brain atlas, and immediately frozen in liquid nitrogen until use.

\section{Immunohistochemistry and immunofluorescence analysis} Using a cryotome (CM1860; Leica, Mannheim, Germany), $40-\mu \mathrm{m}$-thick coronal sections were cut, and were then stored in anti-freezing solution (30\% ethylene glycol and $30 \%$ glycerol in phosphate-buffered saline) at $-20^{\circ} \mathrm{C}$. For immunohistochemical (IHC) staining, sections were treated with $3 \% \mathrm{H}_{2} \mathrm{O}_{2}$ and $4 \%$ BSA to inactivate endogenous peroxidation and block non-specific binding, respectively. Sections were incubated with primary antibodies overnight and incubated with biotinylated secondary 
antibodies for $1 \mathrm{~h}$ at $25^{\circ} \mathrm{C}$ room temperature, followed by an avidin-biotin-HRP complex reagent solution (Vector Laboratories, Burlingame, CA, USA). Subsequently, the peroxidase reaction was performed using diaminobenzidine tetrahydrochloride (Vector Laboratories). For double immunofluorescence (IF) staining, sections were treated to block non-specific binding and were incubated with primary antibodies, followed by secondary antibodies conjugated to a fluorochrome. Detailed information on the primary antibodies used is presented in Additional file 1: Table S2. Digital images of the IHC and IF staining were captured using a Leica DM750 microscope and quantification was performed using Image J. For histological quantification, every fifth $40-\mu \mathrm{m}$-thick section from the region between bregma - $2.69 \mathrm{~mm}$ and $-3.15 \mathrm{~mm}$ (Paxinos mouse brain atlas) was analyzed. Four to six sections per brain were stained and quantified. The number of target protein-positive cells per area $\left(\mathrm{mm}^{2}\right)$ was counted, and the co-localization rate (\%) was calculated using the following formula: $\{$ (the number of target protein-positive cells costained with cell type marker)/the number of cell type marker-positive cells\} $\times 100$.

\section{Statistical analysis}

The differences between experimental groups were determined using one-way analysis of variance, and post-hoc comparisons were made using least significant difference tests. This analysis was conducted using SPSS for Windows, version 18.0 (SPSS Inc., Chicago, IL, USA). All values are reported as mean \pm standard error of mean (SEM). A $p$ value $<0.05$ was considered statistically significant.

\section{Results}

PAP exhibits anti-inflammatory effects in LPS-stimulated microglial cells, mediated through PDE10 inhibition To determine the anti-inflammatory role of PAP, the effect of PAP on the levels of NO and cytokines was investigated. PAP concentrations of 10,20 , and $30 \mu \mathrm{M}$ were used for all experiments since these had no significant effect on cell viability after $24 \mathrm{~h}$ (data not shown). PAP significantly suppressed the production of the proinflammatory molecules NO, TNF- $\alpha$, and IL-1 $\beta$ and increased the production of the anti-inflammatory cytokine IL-10 in LPS-stimulated BV2 cells (Fig. 1a). Data from the Western blot analysis showed that PAP reduced the protein expression of iNOS, TNF- $\alpha$, and IL$1 \beta$ and increased the expression of IL-10 in BV2 cells (Fig. 1b). Using RT-PCR, we found that PAP regulated the expression of iNOS and cytokines at the mRNA level (Fig. 1c). PAP also inhibited LPS-induced expression of iNOS, TNF- $\alpha$, and IL-1 $\beta$ in primary microglia (Additional file 2: Figure S1). Since PAP is a PDE10 inhibitor, we examined whether PDE10 inhibition recapitulates the effect of PAP. PDE10 knockdown by siRNA suppressed NO, TNF- $\alpha$, and IL- $1 \beta$ production and increased IL-10 production in LPS-stimulated BV2 cells (Fig. 1d, e), suggesting that the anti-inflammatory effects of PAP are at least partly mediated through PDE10 inhibition.

PAP inhibits the phosphorylation of MAPKs and Akt, and the activities of NF-kB and AP-1 in LPS-stimulated BV2 microglial cells

We also examined the effect of PAP on MAPKs and the PI3K/Akt signaling pathway, known to play an important role in proinflammatory gene expression by modulating transcription factors such as NF-kB and AP-1 [41, 42]. PAP inhibited LPS-induced phosphorylation of MAPKs and Akt in BV2 cells (Fig. 2a). The DNA binding activity and reporter gene activity of both NF- $\mathrm{kB}$ and $\mathrm{AP}-1$ were also inhibited by PAP in LPS-stimulated BV2 cells (Fig. $2 \mathrm{~b}, \mathrm{c})$, suggesting that PAP regulates inflammatory responses partly by modulating PI3K/Akt, MAPKs, NF-kB, and AP-1 signaling pathways.

PAP inhibits ROS production by suppressing the mRNA expression and phosphorylation of p47phox, a component of NADPH oxidases, and enhancing the Nrf2/ ARE signaling pathway

Reactive oxygen species (ROS) are known to be early signaling inducers in inflammatory responses [43]. Thus, we investigated the effect of PAP on ROS production in LPS-stimulated BV2 cells. DCF-DA assay data showed that PAP inhibited the production of intracellular ROS induced by LPS (Fig. 3a). Since NADPH oxidases are major enzymes involved in ROS generation, we investigated whether PAP influences the components of these enzymes. As shown in Fig. 3b, PAP suppressed the mRNA expression of $\mathrm{p} 47$ phox, but not other components, in LPS-stimulated BV2 cells. In addition, PAP inhibited LPS-induced phosphorylation of p47phox (Fig. 3c). Next, we examined the effect of PAP on antioxidant Nrf2/ARE signaling. EMSA data showed that PAP enhanced LPSinduced Nrf2 binding to ARE (Fig. 3d). Moreover, PAP induced ARE-driven luciferase activity in the absence and presence of LPS (Fig. 3e).

The PKA/CREB pathway plays a crucial role in the antiinflammatory effect of PAP

We investigated whether PAP affects intracellular cAMP level by modulating PDE. As expected, PAP increased cAMP level in BV2 cells in the presence and absence of LPS (Fig. 4a). PAP also increased CREB phosphorylation (Fig. 4b) and other CREB activities such as DNA binding, transcriptional activity, and nuclear translocation (Fig. 4c-e). To determine whether the PKA/ CREB pathway is involved in the anti-inflammatory 


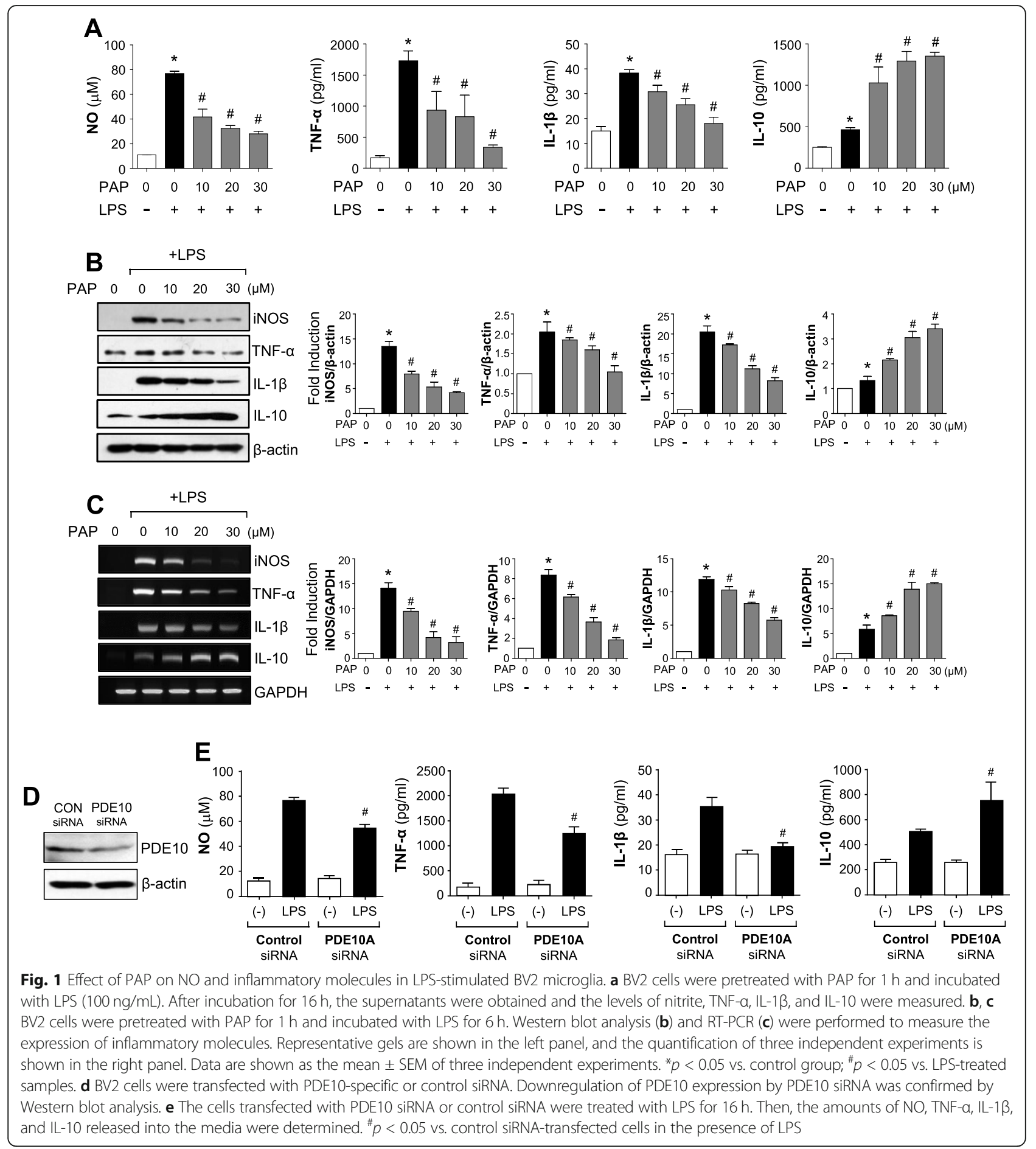

mechanism of PAP, BV2 cells were pre-treated with a PKA inhibitor, H89, before PAP and LPS stimulation. The data showed that $\mathrm{H} 89$ significantly attenuated PAP-mediated suppression of NO, TNF- $\alpha$, IL- $1 \beta$, and ROS and attenuated PAP-induced IL-10 production (Fig. 4f). Overall, these results indicate that the PKA pathway plays a pivotal role in the anti-inflammatory/ antioxidant mechanisms of PAP.

\section{PAP increases PPARy and Nrf2/ARE signaling, in which} PKA is an upstream modulator

Next, we examined the effect of PAP on PPARy, a key transcription factor for the resolution of inflammation [44]. PAP increased the transcriptional activity of PPAR $\gamma$, as shown by the cell-based reporter gene assay in BV2 cells (Fig. 5a). To determine whether PPAR $\gamma$ has an effect on the anti-inflammatory role of 

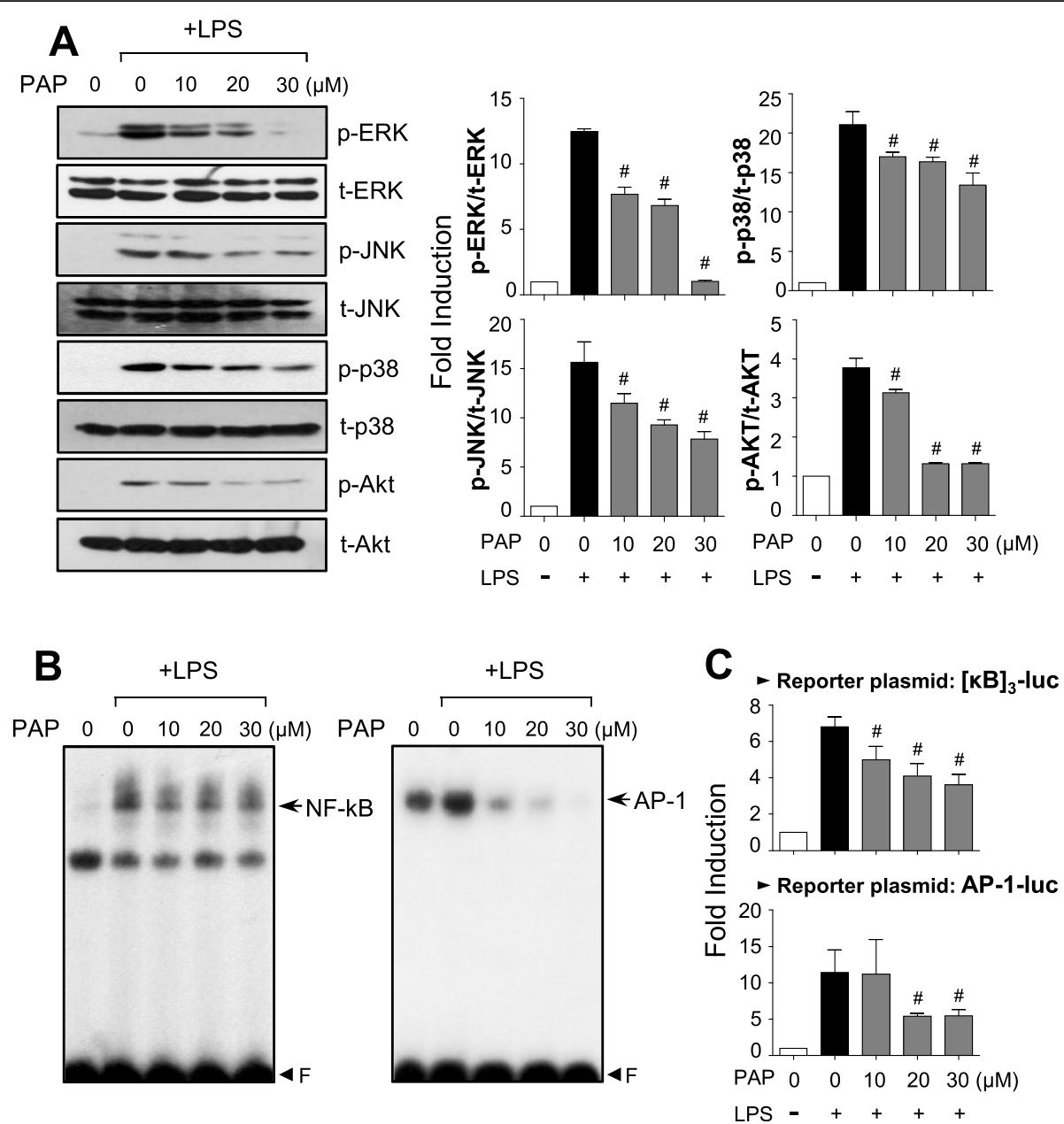

Fig. 2 Effect of PAP on MAPKs, Akt, and NF-KB/AP-1 activities in LPS-stimulated BV2 cells. a Cell lysates were prepared from BV2 cells treated with LPS for 30 min in the absence or presence of PAP, and Western blotting was performed to determine the effect of PAP on MAPKs and Akt activity. Quantification data are shown in the right panels $(n=3)$. Levels of the phosphorylated forms of MAPKs and Akt were normalized to the total forms and expressed as fold changes vs. untreated control samples, which were arbitrarily set to 1. $\mathbf{b}$ EMSA for NF-KB and AP-1 was performed using nuclear extracts prepared from BV2 cells treated with PAP in the presence of LPS for $3 \mathrm{~h}$. c Transient transfection analysis of $[\mathrm{KB}]_{3}-\mathrm{luc}$, and AP-1-luc reporter gene activity. Data are shown as the mean \pm SEM of three independent experiments. ${ }^{\#} p<0.05$ vs.

LPS-treated samples

PAP, a siRNA knockdown experiment was performed. Data from the PPARY siRNA transfection showed that the anti-inflammatory effect of PAP is partially reversed by PPAR $\gamma$ knockdown (Fig. 5b), suggesting that PPAR $\gamma$ plays an important role in the action of PAP. To investigate whether the upregulation of PPARy is related to PKA signaling, BV2 cells were treated with $\mathrm{H} 89$ before LPS/PAP treatment and a PPRE-luc reporter gene assay was performed. As shown in Fig. 5c, H89 attenuated the effect of PAP on PPRE-luc activity. Moreover, H89 reversed the effect of PAP on ARE-luc activity (Fig. 5d). These data suggest that PKA plays a role as an upstream modulator of PPAR $\gamma$ and Nrf2/ARE signaling in LPS/ PAP-treated BV2 cells.
PAP inhibits microglial activation and proinflammatory gene expression, which is reversed by the PKA inhibitor $\mathrm{H} 89$, in the brains of LPS-injected mice

To verify the effects of PAP in vivo, PAP was injected into mice prior to LPS administration. After 3 days of LPS injection, microglial activation and the expression of proinflammatory molecules were evaluated in LPSinjected mouse brains. Systemic LPS increased the number of Iba-1-positive cells in the cortex, hippocampus, and substantia nigra. PAP decreased the number of these cells, indicating that this suppressed microglial activation (Fig. 6a, b). Moreover, PAP suppressed the mRNA expression of iNOS, proinflammatory cytokines, matrix metalloproteinases (MMPs; MMP-3, MMP-8), and tolllike receptors (TLRs; TLR2, TLR4) and increased the 


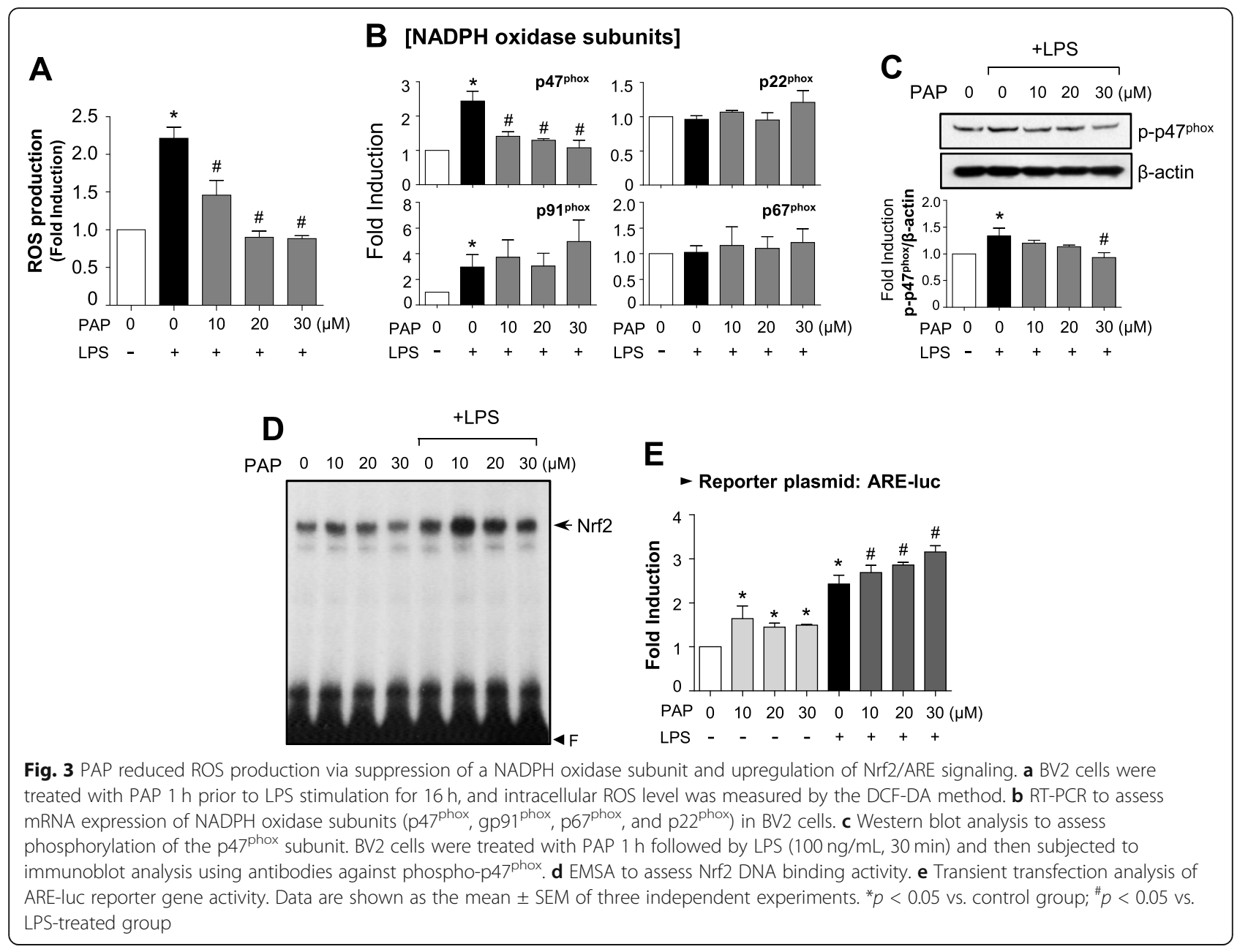

expression of the anti-inflammatory cytokine IL-10 in LPS-injected mouse brains (Fig. 6c, d). Next, to investigate whether PKA signaling is also involved in the antiinflammatory effect of PAP in vivo, H89 was injected $1 \mathrm{~h}$ before every PAP injection. As shown in Fig. 6 a and e, H89 treatment reversed the PAP-mediated suppression of microglial activation and iNOS, TNF- $\alpha$, and IL- $1 \beta$ expression. These results indicate that the PKA pathway is also involved in the anti-inflammatory action of PAP in LPS-injected mouse brains.

PAP exerts anti-inflammatory and neuroprotective effects in MPTP-induced PD model mice

We investigated whether PAP has anti-inflammatory and neuroprotective effects in MPTP-induced PD model mice. An injection of PAP was administered once a day for 3 days before MPTP injection, and mice were sacrificed 7 days later for analysis to be conducted. Dopaminergic neuronal cell death was measured by tyrosine hydroxylase $(\mathrm{TH})$ staining. The data showed that PAP recovered MPTP-mediated neuronal cell death in the substantia nigra and striatum (Fig. 7a; $\mathrm{SN}, \mathrm{F}_{3,12}=49.25$, $p<0.01$; striatum, $\left.\mathrm{F}_{3,12}=49.24, p<0.01\right)$. Moreover, PAP exerted anti-inflammatory effects by reducing MPTP-induced microglial activation (Fig. 7b; $F_{3,12}=$ 9.33, $p<0.01$ ), and the mRNA levels of proinflammatory cytokines and enhancing the mRNA level of the antiinflammatory cytokine IL-10 (Fig. 7)c. Representative high-magnification images of microglia are shown in Additional file 2: Figure S2.

The anti-inflammatory and neuroprotective effects of PAP are dependent on the PKA/CREB signaling pathway in MPTP-induced PD model mice

To investigate whether the PKA pathway also governs the anti-inflammatory and neuroprotective effects of PAP in MPTP-injected mice, mice were administered H89 before PAP injection, and behavioral, immunohistochemical, and biochemical analyses were then performed (Fig. 8a). The data from the rotarod and pole tests showed that MPTP injection impaired locomotor activity, and PAP improved this. H89 reversed this effect of PAP (Fig. 8b, c; rotarod, $\mathrm{F}_{5,67}=30.40, p<0.05$; pole, $\mathrm{F}_{5}$, $\left.{ }_{62}=5.95, p<0.05\right)$. In addition, H89 attenuated PAP- 


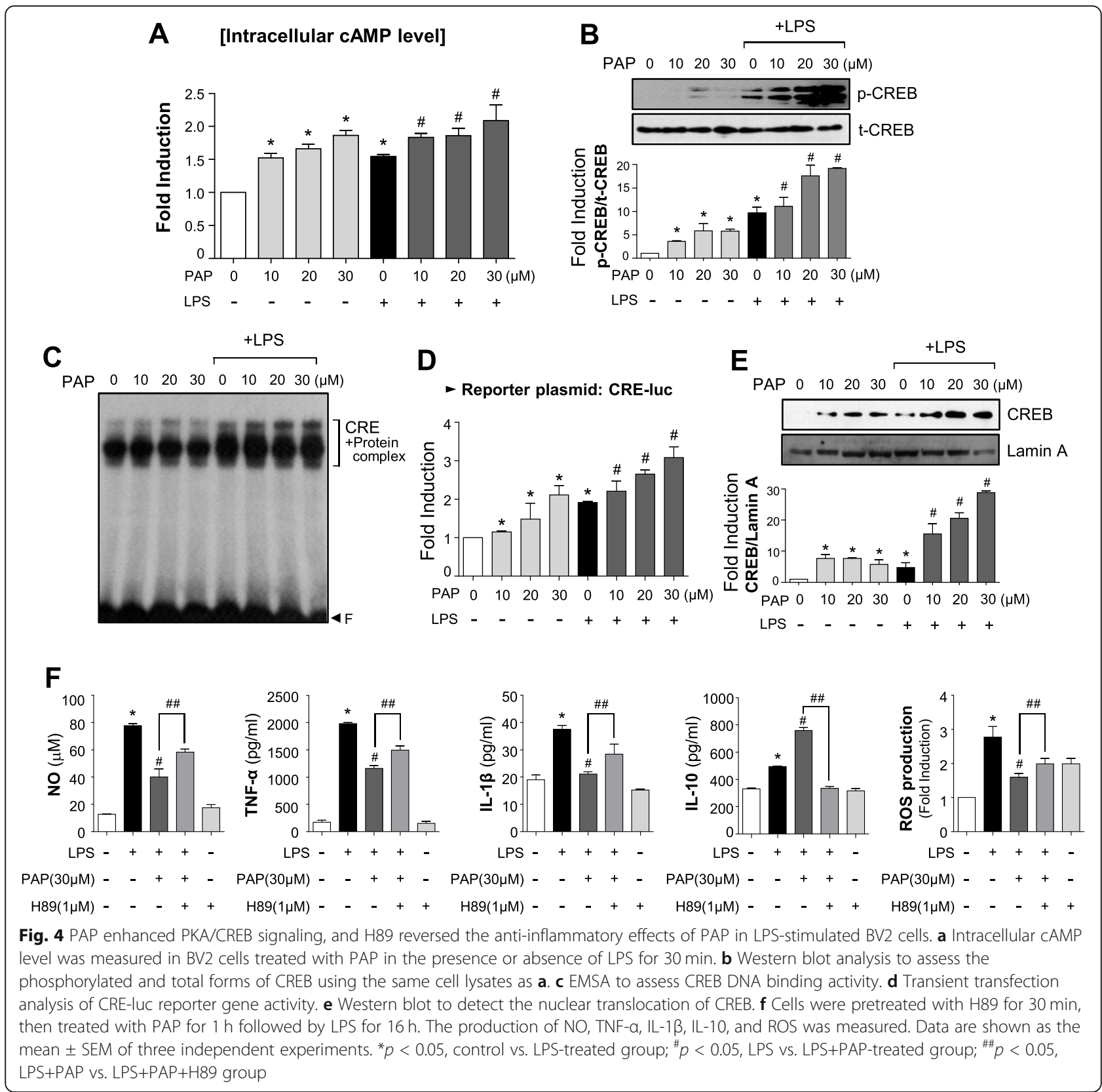

mediated neuroprotection and $\mathrm{PGC}-1 \alpha$ translocation into dopaminergic neurons (Fig. 8d, e; PGC- $1 \alpha, F_{5,37}=$ 13.76, $p<0.01$; PGC- $\left.1 \alpha+\mathrm{TH}, \mathrm{F}_{5,37}=4.15, p<0.01\right)$. In accordance with these data, Western blot analysis showed that MPTP injection reduced the levels of TH and PGC- $1 \alpha$, and this was recovered by PAP. Once again, the effects of PAP were reversed by H89 treatment (Fig. 8f, g). Next, we examined the effect of PAP and $\mathrm{H} 89$ on CREB phosphorylation and its downstream neurotrophic factors BDNF, GDNF, and $\mathrm{Bcl} 2$ by IHC and Western blot analyses. MPTP injection led to a reduction in the protein levels of p-CREB, BDNF, GDNF, and $\mathrm{Bcl} 2$ in the substantia nigra, and these were all recovered by PAP treatment (Fig. 9; pCREB, $\mathrm{F}_{5,18}=31.84, p<$ $0.01 ; \mathrm{pCREB}+\mathrm{TH}, \mathrm{F}_{5,18}=30.35, p<0.01$; GDNF SNpc, $\mathrm{F}_{5,36}=7.69, p<0.01$; GDNF SN, $\mathrm{F}_{5,36}=4.50, p<0.01$ ). However, H89 treatment attenuated the effects of PAP. High-magnification images of GDNF-positive cells in the SN are shown in Additional file 2: Figure S3. Finally, we examined the effect of $\mathrm{H} 89$ on microglial activation in the brains of MPTP/PAP-injected mice. As shown in Fig. 10, H89 also reversed PAP-mediated microglial inactivation $\left(\mathrm{F}_{5,37}=29.20, p<0.01\right)$ and CREB phosphorylation in microglia $\left(\mathrm{F}_{5,18}=22.20, p<0.01\right)$. The data collectively 


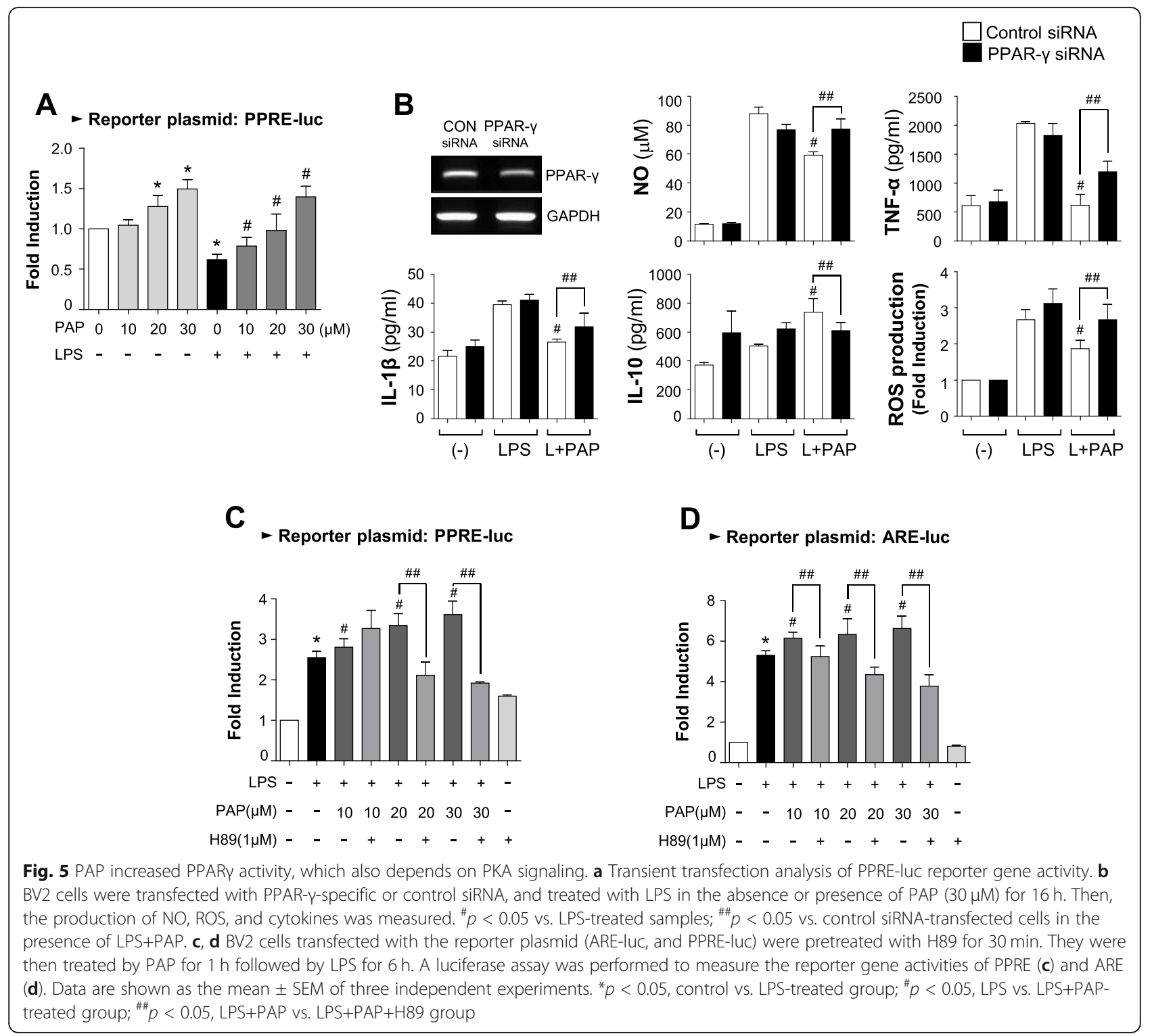

support the critical role of PKA in the neuroprotective and anti-inflammatory functions of PAP in the brains of PD model mice.

\section{Discussion}

In the first part of this study, we demonstrated the antiinflammatory effects of PAP in LPS-stimulated BV2 microglia. PAP exerts anti-inflammatory effects by suppressing proinflammatory molecules such as NO, proinflammatory cytokines, and ROS and enhancing the antiinflammatory cytokine IL-10. These anti-inflammatory effects are mediated via the downregulation of MAPKs, PI3K/Akt, and NF-kB and the upregulation of PKA, Nrf2/ARE, and PPAR $\gamma$ signaling pathways. Blocking PKA signaling reverses the action of PAP, suggesting that the PKA pathway plays a major role in the anti- inflammatory mechanisms of PAP in LPS-stimulated microglia. In the second part of this study, we demonstrated the anti-inflammatory and neuroprotective effects of PAP in LPS- or MPTP-injected mouse model. PAP exerts anti-inflammatory effects by inhibiting microglial activation and the expression of proinflammatory mediators in LPS-injected mouse brains. In addition, PAP exerts neuroprotective effects by recovering the neuronal cell death and impaired locomotor activity induced by MPTP in mice. PAP also exerts antiinflammatory effects in MPTP-injected mice by suppressing microglial activation and the expression of proinflammatory cytokines. Finally, the effect of the PKA inhibitor H89 on the anti-inflammatory and neuroprotective effects of PAP indicates the importance of the PKA pathway in mediating these effects. 


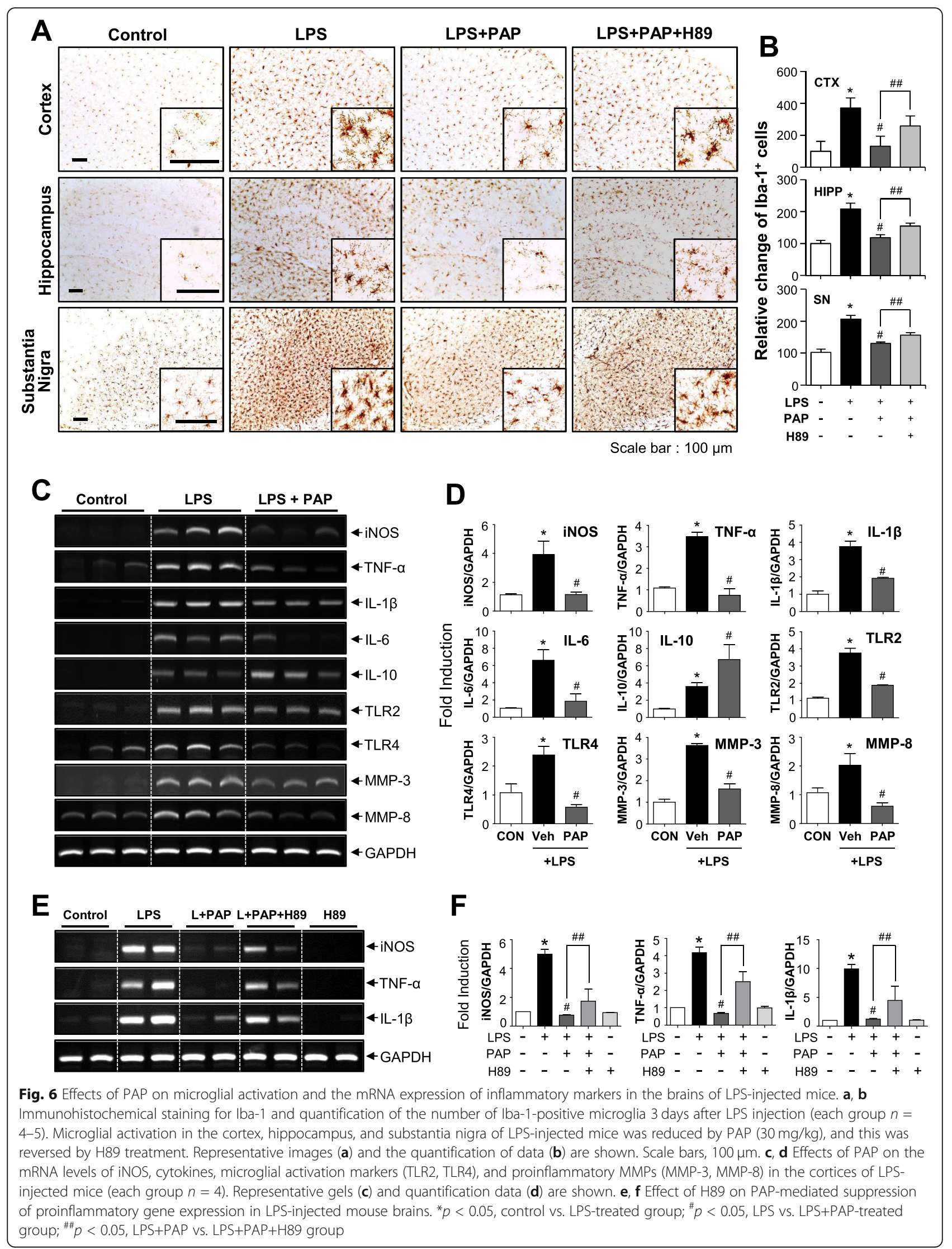




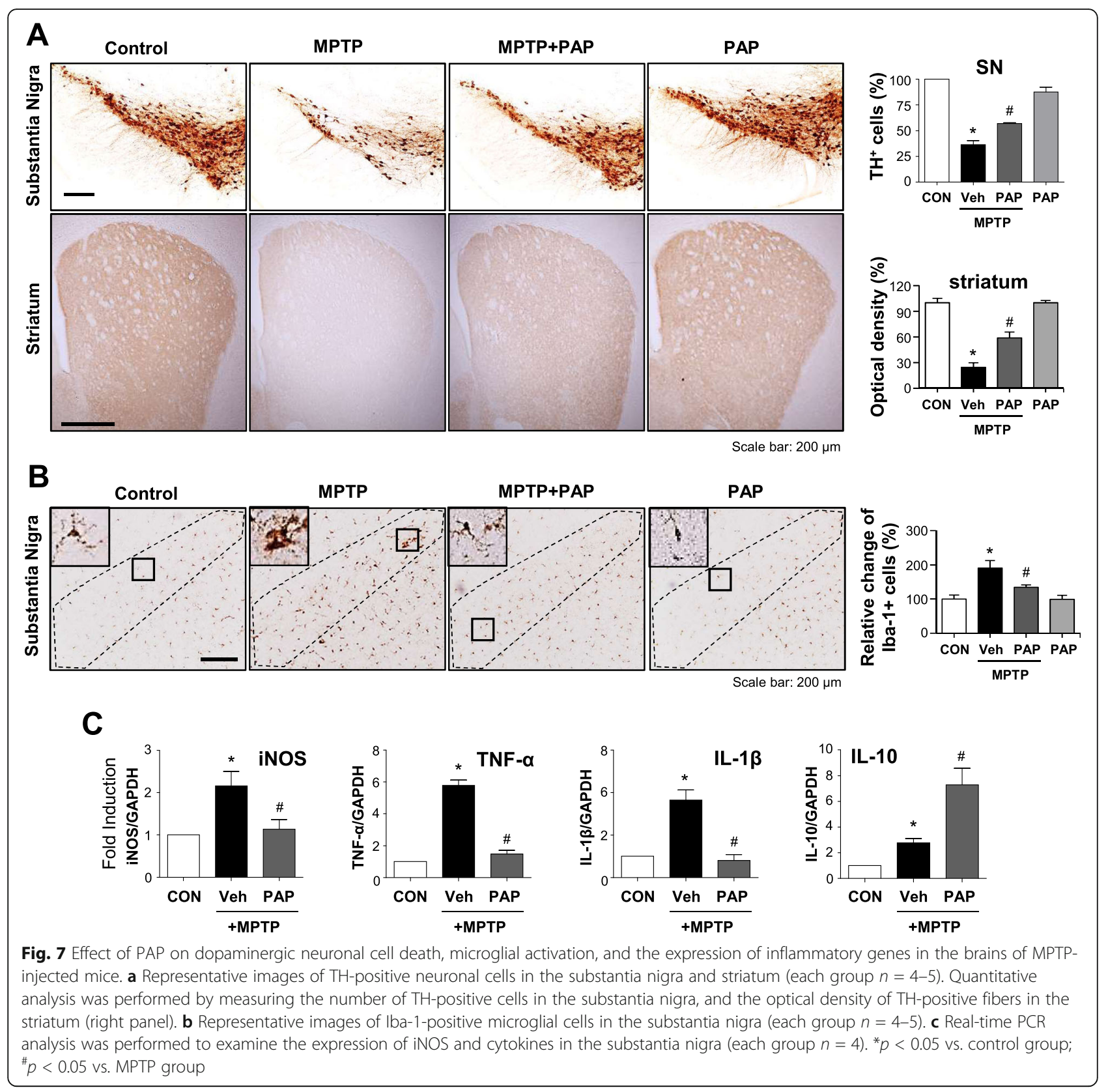

$\mathrm{PD}$ is a neurodegenerative disease characterized by the preferential death of the dopaminergic neurons in the substantia nigra innervating the striatum. The symptoms of this disease include resting tremor, rigidity, bradykinesia, and postural instability [45]. There currently exists no cure for $\mathrm{PD}$, but various therapies are utilized to improve symptoms, namely pharmacological agents, surgery, and physical exercise. Currently, PDE inhibitors are undergoing clinical trials for neurodegenerative and neuropsychiatric disorders such as $\mathrm{HD}$, AD, schizophrenia, and depression [46]. However, no clinical trials are currently exploring the use of a PDE inhibitor for PD. There exist eleven families of PDE, one of which is
PDE10A. This is particularly expressed in the medium spiny neurons of the striatum, and acts to integrate dopaminergic and glutamatergic signal transduction by modulating cAMP/cGMP levels. PDE10A helps to regulate synaptic transmission, neuronal excitability, and synaptic plasticity [37]. Therefore, PDE10 has been suggested as a logical target for the correction of striatal dopamine receptor signaling, which is known to be deficient in PD [46, 47]. In the present study, we found that the selective PDE10 inhibitor PAP rescued impaired movement in MPTP-injected PD mice, demonstrated using the rotarod and pole tests. Moreover, PAP increased the expression of neuronal survival factors such 


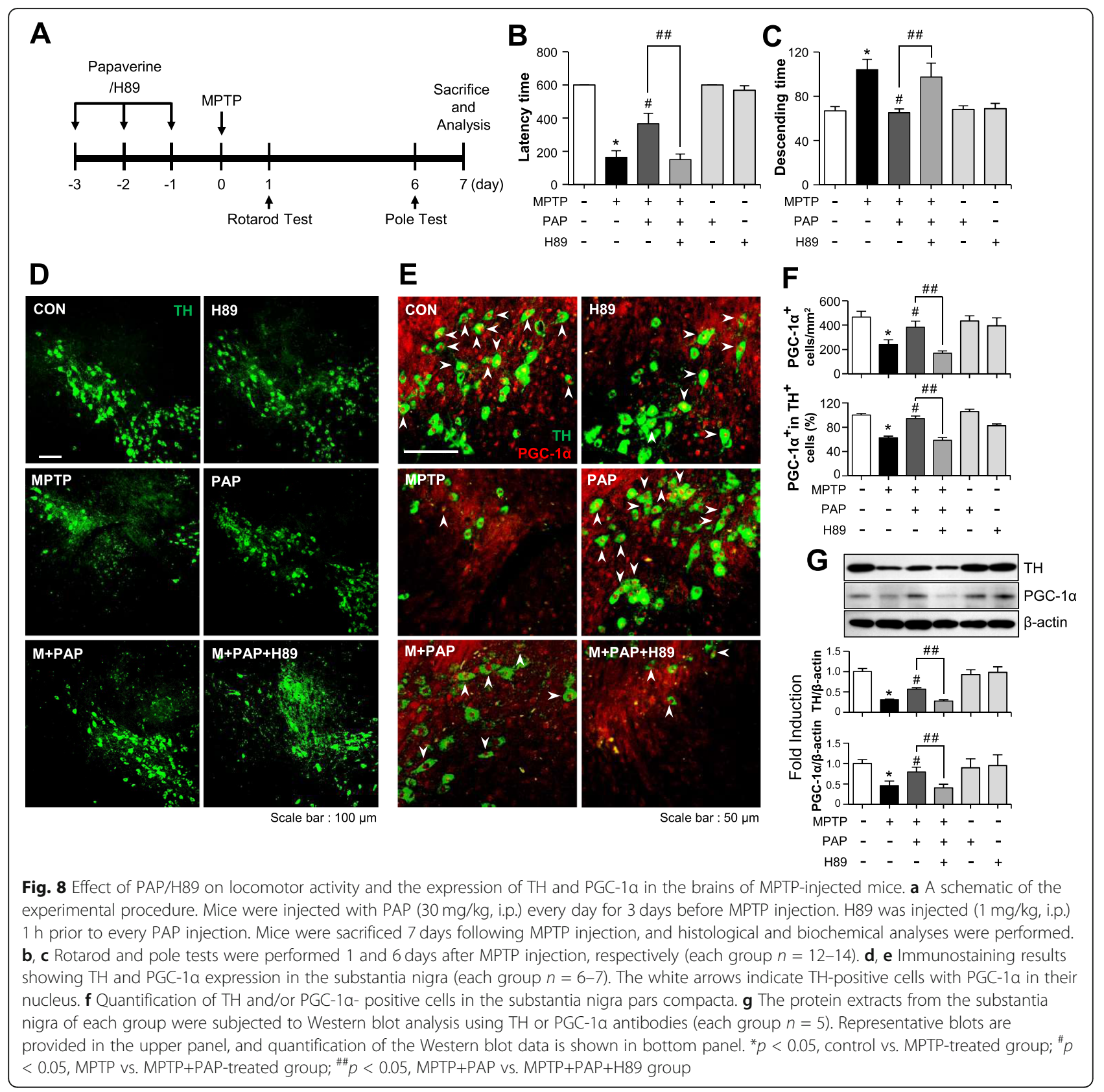

as BDNF, GDNF, Bcl2, and PGC- $1 \alpha$ that are under the control of PKA/CREB signaling, thereby promoting the survivability of dopaminergic neurons in the substantia nigra. Previous studies have reported that PAP induces reversible opening of the $\mathrm{BBB}$ and mediates transient $\mathrm{BBB}$ permeability $[48,49]$. These findings therefore suggest that PAP may be a potential therapeutic agent for PD.

Previous studies have reported that the PKA/CREB pathway contributes to the resolution of inflammation and ROS detoxification [50-52]. This anti-inflammatory effect is closely related to CREB-mediated upregulation of the anti-inflammatory cytokine IL-10 and inhibition of proinflammatory cytokines such as TNF- $\alpha$ [53, 54]. CREB also induces the expression of PGC- $1 \alpha$, a key effector of ROS detoxifying enzyme expression and mitochondrial biogenesis [23]. Furthermore, we previously demonstrated that the PKA/CREB pathway governs the expression of hemeoxygenase-1 in microglial cells [52]. In addition to CREB, the present study found that PAP also increased the activities of Nrf2 and PPAR- $\gamma$, which have anti-inflammatory/antioxidant functions by inhibiting NF- $\mathrm{kB}$ and ROS production in microglia $[38,44,55]$. Interestingly, PKA inhibition by $\mathrm{H} 89$ reversed this, suggesting that PKA is an upstream modulator of Nrf2 and 


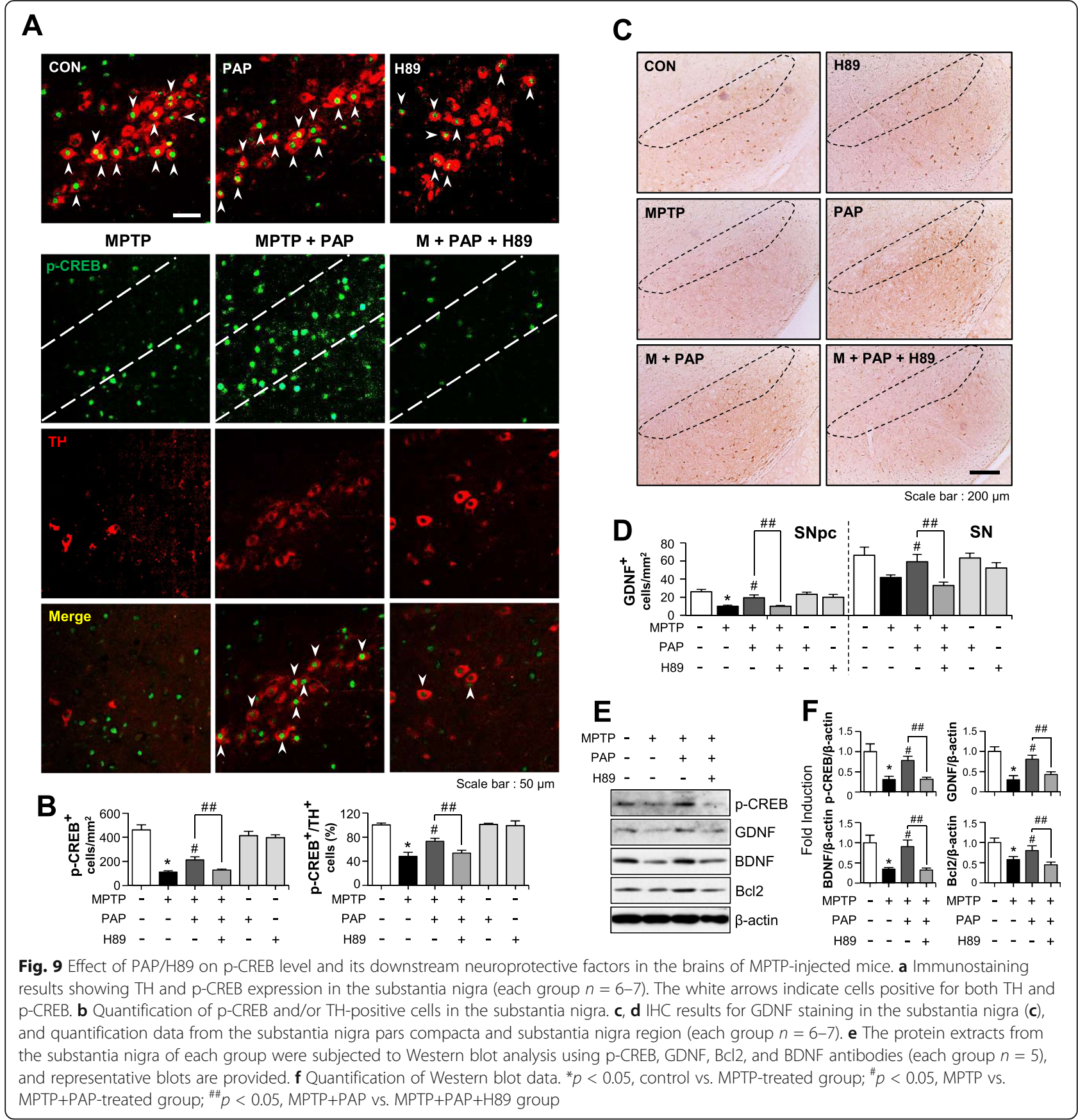

PPARy. Our data collectively suggest that PKA is the master regulator of the anti-inflammatory and antioxidant functions of PAP in activated microglia.

As a potent PDE10 inhibitor, PAP activates cAMP/ PKA signaling in striatopallidal and striatonigral medium spiny neurons. This leads to the inhibition of dopamine D2 receptor signaling in striatopallidal neurons, and the potentiation of dopamine D1 receptor signaling in striatonigral neurons. Therefore, PDE10 inhibition by PAP has been suggested as a therapeutic target for neuropsychotic disorders such as schizophrenia [27, 56].
Moreover, PAP improved cognitive impairment in a R6/ 1 HD mouse model, partly by increasing hippocampal pGluA1 and p-CREB levels, suggesting a potential role in HD treatment [30]. However, the therapeutic effect of PAP in PD models has not been reported until now. In the present study, we demonstrated that PAP suppressed microglial activation and recovered dopaminergic neuronal cell death via PKA signaling in sepsis and PD model mice. Using siRNA knockdown experiments, we demonstrated that the anti-neuroinflammatory effects of PAP are mediated through PDE10. In support of this, we 


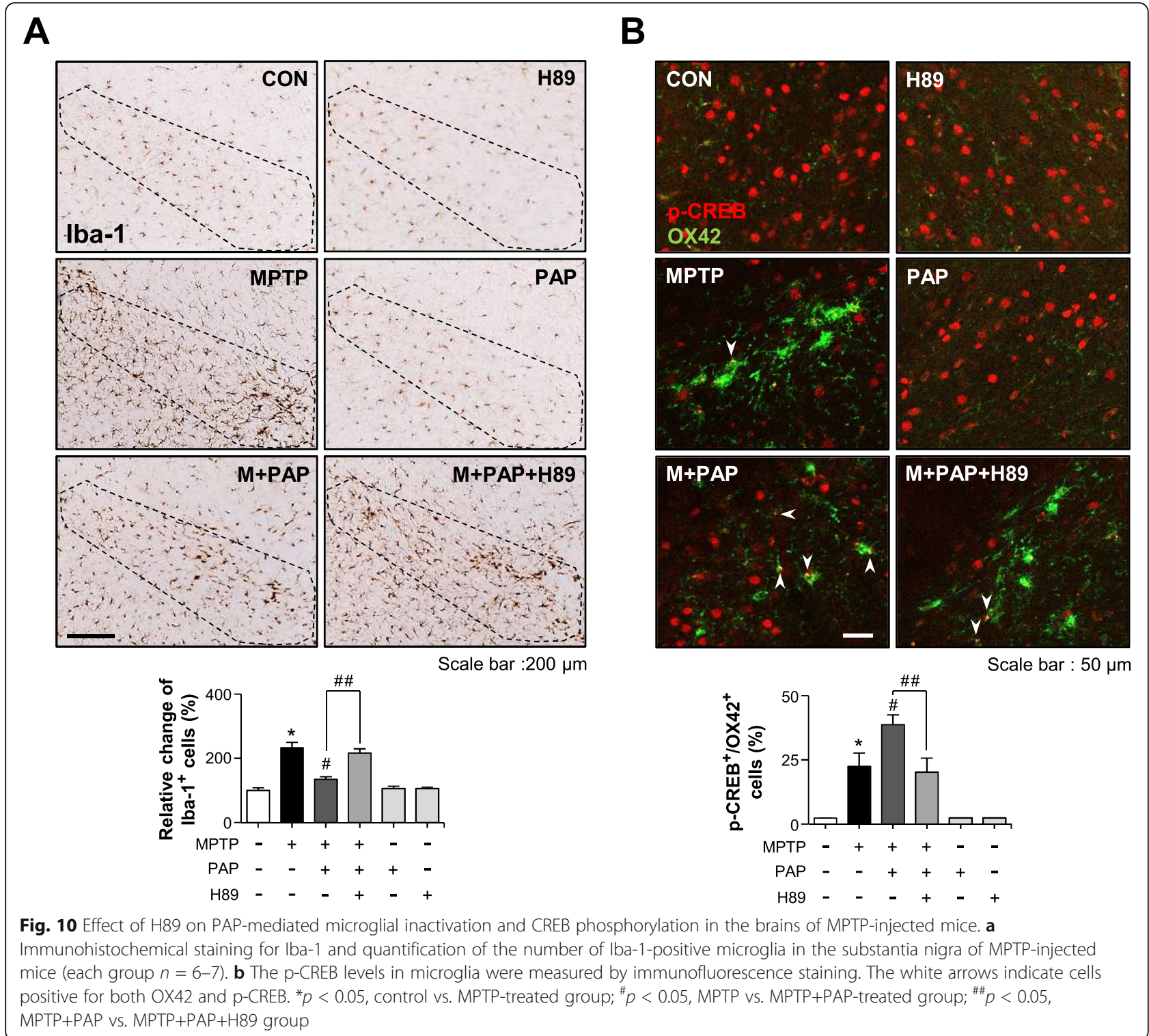

found that MP-10 (PF-02545920), a highly selective and potent PDE10 inhibitor, recapitulates the effect of PAP in LPS-stimulated microglia and septic mouse brains (data not shown). However, we cannot exclude the possibility that a PDE10-independent mechanism is also involved in the anti-inflammatory and neuroprotective effects of PAP. Further study is therefore warranted to address this issue.

\section{Conclusions}

The present study reports, for the first time, the antiinflammatory and neuroprotective effects of PAP in systemic inflammation and PD mouse models. We demonstrated that the PKA signaling pathway plays a key role in the anti-inflammatory and neuroprotective mechanisms of PAP by modulating various downstream effectors. Therefore, PAP may be a promising therapeutic candidate for neuroinflammatory and neurodegenerative disorders such as PD.

\section{Supplementary information}

Supplementary information accompanies this paper at https://doi.org/10. 1186/s12974-019-1649-3.

Additional file 1: Table S1. List of primary antibodies used in Western blot analysis. Table S2. List of primary antibodies used in immunohistochemical and immunofluorescence staining

Additional file 2: Figure S1. Effect of PAP on the expression of iNOS, TNF- $a$, and IL-1 $\beta$ in LPS-stimulated rat primary microglia. Figure S2. Morphological changes of microglia in response to MPTP. Figure S3. High magnification images of GDNF-positive cells in the substantia nigra of MPTP-injected mice 


\section{Abbreviations}

AP-1, : Activator protein-1; ARE, : Antioxidant response element; BBB, : Bloodbrain barrier; BDNF, : Brain-derived neurotrophic factor; CAMP, : Adenosine 3',5'-cyclic monophosphate; CREB, : CAMP response element-binding protein; EMSA, : Electrophoretic mobility shift assay; ERK, : Extracellular signalregulated kinase; GDNF, : Glial cell line-derived neurotrophic factor; HD, : Huntington's disease; IF, : Immunofluorescence; IHC, : Immunohistochemical; IL, : Interleukin; iNOS, : Inducible nitric oxide synthase; LPS, : Lipopolysaccharide; MAPK, : Mitogen-activated protein kinase; MMP, : Matrix metalloproteinase; MPTP, : 1-Methyl-1,2,3,6-tetrahydropyridine; NF-KB, : Nuclear factor-KB; NO, : Nitric oxide; Nrf2, : Nuclear factor-erythroid 2 (NF-E2)-related factor 2; PAP, : Papaverine; PD, : Parkinson's disease; PDE, : Phosphodiesterase; PI3K, : Phosphoinositol 3-kinase; PKA, : Protein kinase A; PPAR, : Peroxisome proliferator-activated receptor; ROS, : Reactive oxygen species; siRNA, : Small interference RNA; SN, : Substantia nigra; TH, : Tyrosine hydroxylase; $T L R$, : Toll-like receptor; TNF, : Tumor necrosis factor

\section{Acknowledgements}

Not applicable

\section{Authors' contributions}

YYL and JSP designed the study, performed the experiments, and wrote the manuscript. YHL, JEP, and DK performed the experiments and analyzed the data. YC, EP, and JK helped in the preparation of the manuscript. HK supervised the design of the study and analyzed the data and wrote the manuscript. All authors read and approved the final manuscript.

\section{Funding}

This research was supported by the National Research Foundation of Korea (NRF) grant funded by the Korea government (MSIT) (2018R1A2B6003074).

\section{Availability of data and materials}

The datasets used and/or analyzed during the current study are available from the corresponding author on reasonable request.

\section{Ethics approval and consent to participate}

Not applicable

\section{Consent for publication}

Not applicable

\section{Competing interests}

The authors declare that they have no competing interests.

\section{Author details}

'Department of Molecular Medicine and Tissue Injury Defense Research Center, School of Medicine, Ewha Womans University, 808-1 Magok-dong, Gangseo-gu, Seoul 07804, South Korea. ${ }^{2}$ Department of Physiology and Tissue Injury Defense Research Center, School of Medicine, Ewha Womans University, Seoul, South Korea. ${ }^{3}$ Department of Pharmacology and Tissue Injury Defense Research Center, School of Medicine, Ewha Womans University, Seoul, South Korea. ${ }^{4}$ Department of Brain \& Cognitive Sciences, Ewha Womans University, Seoul, South Korea.

Received: 29 August 2019 Accepted: 19 November 2019

Published online: 02 December 2019

\section{References}

1. Amor S, Peferoen LA, Vogel DY, Breur M, van der Valk P, Baker D, van Noort JM. Inflammation in neurodegenerative diseases-an update. Immunology. 2014;142:151-66.

2. Chitnis T, Weiner HL. CNS inflammation and neurodegeneration. J Clin Invest. 2017;127:3577-87

3. Prinz M, Priller J. Microglia and brain macrophages in the molecular age: from origin to neuropsychiatric disease. Nat Rev Neurosci. 2014;15:300-12

4. Tremblay MË, Stevens B, Sierra A, Wake H, Bessis A, Nimmerjahn A. The role of microglia in the healthy brain. J Neurosci. 2011;31:16064-9.

5. Cherry JD, Olschowka JA, O'Banion MK. Neuroinflammation and M2 microglia: the good, the bad, and the inflamed. J Neuroinflammation. 2014; 11:98.
6. Subramaniam SR, Federoff HJ. Targeting microglial activation states as a therapeutic avenue in Parkinson's disease. Front Aging Neurosci. 2017:9:176.

7. Dauer W, Przedborski S. Parkinson's disease: mechanisms and models. Neuron. 2003;39:889-909.

8. Fujiwara H, Hasegawa M, Dohmae N, Kawashima A, Masliah E, Goldberg MS, Shen J, Takio K, Iwatsubo T. Alpha-synuclein is phosphorylated in synucleinopathy lesions. Nat Cell Biol. 2002;4:160-4.

9. Dzamko N, Geczy CL, Halliday GM. Inflammation is genetically implicated in Parkinson's disease. Neuroscience. 2015;302:89-102.

10. Ghosh M, Aguirre V, Wai K, Felfly H, Dietrich WD, Pearse DD. The interplay between cyclic AMP, MAPK, and NF-KB pathway in response to proinflammatory signals in microglia. Biomed Res Int. 2015;2105:308461.

11. Song GH, Suk K. Pharmacological modulation of functional phenotypes of microglia in neurodegenerative diseases. Front Aging Neurosci. 2017;9:139.

12. Ghosh $M, X u Y$, Pearse DD. Cyclic AMP is a key regulator of $M 1$ and $M 2 a$ phenotype conversion of microglia in the presence of Th2 cytokines. J Neuroinflammation. 2016;13:9.

13. Pearse DD, Hughes ZA. PDE4B as a microglia target to reduce neuroinflammation. Glia. 2016;6:1698-709.

14. Guo H, Cheng Y, Wang C, Wu J, Zou Z, Niu B, Yu H, Wang H, Xu J. FFPM, a PDE4 inhibitor, reverses learning and memory deficits in APP/PS1 transgenic mice via CAMP/PKA/CREB signaling and anti-inflammatory effects. Neuropharmacology. 2017;116:260-9.

15. Schwenkgrub J, Zaremba M, Joniec-Maciejak I, Cudna A, Mirowska-Guzel D, Kurkowska-Jastrzebska I. The phosphodiesterase inhibitor, ibudilast, attenuates neuroinflammation in the MPTP model of Parkinson's disease. PLoS One. 2017;12:e0182019.

16. Bertolino A, Crippa D, Dio SD, Fichte K, Musmeci G, Porro V, Sastre $Y$, Hermande M, Schratzer M. Rolipram versus imipramine in inpatients with major, "minor" or atypical depressive disorder: a double blinded-dummy study aimed at testing a novel therapeutic approach. Int Clin Psychopharmacol. 1988;3:245-53.

17. Richter W, Menniti FS, Zhang HT, Conti M. PDE4 as a target for cognition enhancement. Expert Opin Ther Targets. 2013;17:1011-27.

18. Han X, Lamshoft M, Grobe N, Ren X, Fist AJ, Kutchan TM, Spiteller M, Zenk $\mathrm{MH}$. The biosynthesis of Papaverine proceeds via (S)-reticuline. Phytochemistry. 2010;71:1305-12.

19. Kim JH, Yi HJ, Ko Y, Kim YS, Kim DW, Kim JM. Effectiveness of papaverine cisternal irrigation for cerebral vasospasm after aneurysmal subarachnoid hemorrhage and measurement of biomarkers. Neurol Sci. 2014;35:715-22.

20. Zhu W, Liu S, Zhao J, Liu S, Jiang S, Li B, Yang H, Fan C, Cui W. Highly flexible and rapidly degradable papaverine-loaded electrospun fibrous membranes for preventing vasospasm and repairing vascular tissue. Acta Biomater. 2014;10:3018-28.

21. Grauer SM, Pulito VL, Navarra RL, Kelly MP, Kelley C, Graf R, Langen B, Logue $S$, Brennan J, Jiang $L$, et al. Phosphodiesterase PDE10A inhibitor activity in preclinical models of the positive, cognitive, and negative symptoms of schizophrenia. J Pharmacol Exp Ther. 2009;331:574-90.

22. Siuciak JA, Chapin DS, Harms JF, Lebel LA, McCarthy SA, Chambers L, Shrikhande A, Wong S, Menniti FS, Schmidt CJ. Inhibition of the striatumenriched phosphodiesterase PDE10A: a novel approach to the treatment of psychosis. Neuropharmacology. 2006;51:386-96.

23. Fernandez-Marcos PJ, Auwerx J. Regulation of PGC-1alpha, a nodal regulator of mitochondrial biogenesis. Am J Clin Nutr. 2011:93:884S-90.

24. Seeger TF, Bartlett B, Coskran TM, Culp JS, James LC, Krull DL, Lanfear J, Ryan AM, Schmidt CJ, Strick CA, et al. Immunohistochemical localization of PDE10A in the rat brain. Brain Res. 2003;985:113-26.

25. Giampa C, Laurenti D, Anzilotti S, Bernardi G, Menniti FS, Fusco FR. Inhibition of the striatal specific phosphodiesterase PDE10A ameliorates striatal and cortical pathology in R6/2 mouse model of Huntington's disease. PLoS One. 2009;5:e13417.

26. Wilson LS, Brandon NJ. Emerging biology of PDE10A. Curr Pharm Des. 2015; 21:378-88.

27. Zagorska A, Partyka A, Bucki A, Gawalska A, Czopek A, Pawlowski M. Phosphodiesterase 10 inhibitors - novel perspectives for psychiatric and neurodegenerative drug discovery. Curr Med Chem. 2018;25:1-27.

28. Jankowska A, Swierczek A, Wyska E, Gawalska A, Bucki A, Pawlowski M, Chlon-Rzepa G. Advances in discovery of PDE10A inhibitors for CNS-related disorders. Part 1: overview of the chemical and biological research. Curr Drug Targets. 2019;20:122-43. 
29. Knott EP, Assi M, Rao SN, Ghosh M, Pearse DD. Phosphodiesterase inhibitors as therapeutic approach to neuroprotection and repair. Int J Mol Sci. 2017; 18:E696.

30. Giralt A, Saavedra A, Carreton O, Arumi H, Tyebji S, Alberch J, Perez-Navarro E. PDE10 inhibition increases GluA1 and CREB phosphorylation and improves spatial and recognition memories in a Huntington's disease mouse model. Hippocampus. 2013;23:684-95.

31. Tamada KT, Nakajima S, Ogawa N, Inada M, Shibasaki H, Sato A, Takasawa R, Yoshimori A, Suzuki Y, Watanabe N, et al. Papaverine identified as an inhibitor of high mobility group box 1 /receptor for advance glycation endproducts interaction suppresses high mobility group box 1-mediated inflammatory responses. Biochem Biophys Res Commun. 2019;511:665-70.

32. Yamazaki Y, Kawano Y. Inhibitory effects of herbal alkaloids on the tumor necrosis factor- $a$ and nitric oxide production in lipopolysaccharidestimulated RAW264 macrophages. Chem Pharm Bull. 2011;59:388-91.

33. Yu AK, Datta S, McMackin MZ, Cortopassi GA. Rescue of cell death and inflammation of a mouse model of complex 1-mediated vision loss by repurposed drug molecules. Hum Mol Genet. 2017;26:4929-36.

34. Zhou T, Zhu Y. Cascade signals of papaverine inhibiting LPS-induced retinal microglial activation. J Mol Neurosci. 2019;68:111-9.

35. Bocchini V, Mazzolla R, Barluzzi R, Blasi E, Sick P, Kettenmann H. An immortalized cell line expresses properties of activated microglial cells. J Neurosci Res. 1992;31:616-21.

36. Lee EJ, Ko HM, Jeong YH, Park EM, Kim HS. $\beta$-Lapachone suppresses neuroinflammation by modulating the expression of cytokines and matrix metalloproteinases in activated microglia. J Neuroinflammation. 2015;12:133.

37. Ryoo IG, Kim G, Choi BH, Lee SH, Kwak MK. Involvement of Nrf2 signaling in doxorubicin resistance of cancer stem cell-enriched colonospheres. Biomol Ther. 2016;24:482-8.

38. Choi MJ, Lee EJ, Park JS, Kim SN, Park EM, Kim HS. Anti-inflammatory mechanism of galangin in lipopolysaccharide-stimulated microglia: critical role of PPARy signaling pathway. Biochem Pharmacol. 2017;144:120-31.

39. Park JS, Leem YH, Park JE, Kim DY, Kim HS. Neuroprotective effect of $\beta$ lapachone in MPTP-induced Parkinson's disease mouse model: involvement of astroglial p-AMPK/Nrf2/HO-1 signaling pathways. Biomol Ther. 2019;27:178-84.

40. Rai SN, Yadav SK, Singh D, Singh SP. Ursolic acid attenuates oxidative stress in nigrostriatal tissue and improves neurobehavioral activity in MPTPinduced Parkinsonian mouse model. J Chem Neuroanat. 2016;71:41-9.

41. Chun J, Choi RJ, Khan S, Lee DS, Kim YC, Nam YJ, Lee DU, Kim YS. Alantolactone suppresses inducible nitric oxide synthase and cyclooxygenase-2 expression by down-regulating NF-KB, MAPK, and AP-1 via the MyD88 signaling pathway in LPS-activated RAW 264.7 cells. Int Immunopharmacol. 2012;14:375-83.

42. Kaltschmidt B, Kaltschmidt C. NF-kappaB in the nervous system. Cold Spring Harb Perspect Biol. 2009;1:a001271. (Review. Erratum in: Cold Spring Harb Perspect Biol. 2010;2:a001271.)

43. Bedard K, Krause KH. The NOX family of ROS-generating NADPH oxidases: physiology and pathophysiology. Physiol Rev. 2007;87:245-313.

44. Zolezzi JM, Santos MJ, Bastías-Candia S, Pinto C, Godoy JA, Inestrosa NC. PPARs in the central nervous system: roles in neurodegeneration and neuroinflammation. Biol Rev Camb Philos. 2017;92:2046-69.

45. Sveinbjornsdottir S. The clinical symptoms of Parkinson's disease. J Neurochem. 2016;1:318-24.

46. Nthenge-Ngumbau DN, Mohanakumar KP. Can cyclic nucleotide phosphodiesterase inhibitors be drugs for Parkinson's disease? Mol Neurobiol. 2018;55:822-34.

47. Heckman PR, van Duinen MA, Bollen EP, Nishi A, Wennogle LP, Blokland A, Prickaerts J. Phosphodiesterase inhibition and regulation of dopaminergic frontal and striatal functioning: clinical implications. Int J Neuropsychopharmacol. 2016;19:1-16.

48. Bhattacharjee AK, Kondoh T, Ikeda M, Kohmura E. MMP-9 and EBA immunoreactivity after papaverine mediated opening of the blood-brain barrier. Neuroreport. 2002;13:2217-21.

49. Krishan M, Gudelsky GA, Desai PB, Genter MB. Manipulation of olfactory tight junctions using papaverine to enhance intranasal delivery of gemcitabine to the brain. Drug Deliv. 2014;21:8-16.

50. Kim WK, Jang PG, Woo MS, Han IO, Piao HZ, Lee K, Lee H, Joh TH, Kim HS. A new anti-inflammatory agent $\mathrm{KL}-1037$ represses proinflammatory cytokines and inducible nitric oxide synthase (iNOS) gene expression in activated microglia. Neuropharmacology. 2004;47:243-52.
51. Lee B, Cao R, Choi YS, Cho HY, Rhee AD, Hah CK, Hoy KR, Obrietan K. The CREB/CRE transcriptional pathway: protection against oxidative stressmediated neuronal cell death. J Neurochem. 2009;108:1251-65.

52. Jung JS, Shin JA, Park EM, Lee JE, Kang YS, Min SW, Kim DH, Hyun JW, Shin CY, Kim HS. Anti-inflammatory mechanism of ginsenoside Rh1 in lipopolysaccharide-stimulated microglia: critical role of the protein kinase A pathway and hemeoxygenase-1 expression. J Neurochem. 2010;115:1668-80.

53. Brenner S, Prosch S, Schenke-Layland K, Riese U, Gausmann U, Platzer C. CAMP-induced interleukin-10 promoter activation depends on CCAAT/ enhancer-binding protein expression and monocytic differentiation. J Biol Chem. 2003;278:5597-604.

54. Kast RE. Tumor necrosis factor has positive and negative self regulatory feedback cycles centered around cAMP. Int J Immunopharmacol. 2000; 22:1001-6.

55. Zhao XR, Gonzales N, Aronowski J. Pleiotropic role of PPARy in intracerebral hemorrhage: an intricate system involving Nrf2. RXR, and NF-kB, CNS Neurosci Ther. 2015;21:357-66

56. Nishi A, Kuroiwa M, Miller D, O'Callaghan JP, Bateup HS, Shuto T, Sotogaku N, Fukuda T, Heintz N, Greengard P, et al. Distict roles of PDE4 and PDE10A in the regulation of CAMP/PKA signaling in the striatum. J Neurosci. 2008;28: 10460-71.

\section{Publisher's Note}

Springer Nature remains neutral with regard to jurisdictional claims in published maps and institutional affiliations.
Ready to submit your research? Choose BMC and benefit from:

- fast, convenient online submission

- thorough peer review by experienced researchers in your field

- rapid publication on acceptance

- support for research data, including large and complex data types

- gold Open Access which fosters wider collaboration and increased citations

- maximum visibility for your research: over $100 \mathrm{M}$ website views per year

At BMC, research is always in progress.

Learn more biomedcentral.com/submissions 